\title{
ORFEO, THE PLEIADES ACCOMPANIMENT PROGRAM AND ITS USERS THEMATIC COMMISSIONING
}

\author{
C. Tinel ${ }^{\text {a }, *, \text { M. Grizonnet }}{ }^{\text {a }}$, D. Fontannaz ${ }^{\text {a }}$, H. de Boissezon ${ }^{\text {a }}$, A. Giros ${ }^{\text {a }}$ \\ ${ }^{a}$ CNES, DCT/SI/AP, 18 avenue Edouard Belin, 31401 Toulouse Cedex 9, France (Claire, Tinel)@ cnes.fr
}

Technical Commissions III and I: Pléiades System Applications

KEY WORDS: Pleiades, ORFEO, accompaniment program, thematic commissioning, space applications

\begin{abstract}
:
ORFEO, the PLEIADES Accompaniment Program, was set up by CNES, the French Space Agency, to prepare, accompany and promote the use and the exploitation of the images acquired by this Very High Resolution optical sensor. It was initiated in 2004 and will last until the end of the first year of the satellite life (launched in December 2011).

The Thematic part of the ORFEO accompaniment program covers a large range of applications, and aims at specifying and validating products and services required by users. An in-depth work of user needs assessments in eight thematic domains (sea and coastline, risks and humanitarian aid, cartography and urban planning, geophysical hazards, hydrology, forestry, agriculture and defence) has given rise to a large number of feasibility studies from 2006 to 2011.

The Methodological Part of the ORFEO accompaniment program aims at preparing the use and exploitation of these submetric images. CNES decided to develop Orfeo Toolbox (OTB), an open source library capitalising the methodological know-how as a set of image processing and algorithmic components. Among other, OTB provides a number of heavily documented image processing functionalities such as filtering, feature extraction, segmentation, classification, change detection, 3D extraction, GIS links,....

As a conclusion to the ORFEO program, the PLEIADES Users Thematic Commissioning (UTC) started three months after the satellite launch and will last until mid 2013. It covers a large number of specific interest ORFEO sites, on which PLEIADES images are being intensively acquired and processed. These ORFEO sites have been chosen according to the expectations expressed by the users in terms of their interest for dedicated thematic, their geographic location and their multi-thematic content.

This paper presents the ORFEO program achievements (thematic and methodology) and the organisation of the Users Thematic Commissioning (sites, studies). The paper is illustrated with some examples of multi-thematic studies, lead through ORFEO, covering a large range of applications, and aiming at validating value added products and services provided to end users from PLEIADES imagery.
\end{abstract}

\section{RESUME:}

ORFEO, le programme d'accompagnement de Pléiades, a été mis en place par le CNES, le Centre National d'Etudes Spatiales pour préparer, accompagner et promouvoir l'utilisation et l'exploitation des images optiques à Très Haute Résolution Spatiale. Il a été initié en 2004 et durera jusqu'à la fin de la première année de vie du satellite (lancé en décembre 2011).

Le volet thématique du programme d'accompagnement ORFEO couvre une large gamme d'applications et vise à spécifier et valider des produits à valeur ajoutée et services demandés par les utilisateurs. Un travail en profondeur sur la validation des besoins de $\mathrm{s}$ utilisateurs dans huit domaines thématiques (mer et littoral, risques et aide humanitaire, cartographie et aménagement du territoire, géologie et géophysique, hydrologie, forêt, agriculture et défense) a débouché sur le lancement d'un large nombre d'études de faisabilité de 2006 à 2011.

Le volet méthodologique du programme d'accompagnement ORFEO vise à préparer l'utilisation et l'exploitation de ces images submétriques. Le CNES a décidé de développer l'ORFEO ToolBox (OTB), un logiciel libre capitalisant la connaissance méthodologique en tant que routines algorithmiques et de traitements d'images. Entre autres, OTB propose un nombre élevé de fonctionnalités documentées de traitement d'image telles que le filtrage, l'extraction d'objet, la segmentation, la classification, la détection de changements, l'extraction 3D, les liens avec les SIG...

En conclusion au programme ORFEO, la Recette Thématique Utilisateurs (RTU) a commencé trois mois après le lancement du satellite et durera jusqu'à mi 2013. Elle couvre un grand nombre de sites spécifiques d'intérêt, sur lesquels les images PLEIADES sont intensivement acquises et produites. Ces sites ORFEO ont été choisi en fonction des intérêts exprimés par les utilisateurs pour une thématique donnée, leur site géographique et leur contenu multi-thématiques.

Cet article présente les modalités du programme ORFEO (thématique et méthodologique) et l'organisation de la Recette Thématique Utilisateurs). L'article est illustré avec des exemples d'études thématiques, conduites par ORFEO, couvrant une large gamme d'applications et visant à valider les produits à valeur ajoutée et services fournis aux utilisateurs à partir de l'imagerie PLEIADES.

\footnotetext{
* Corresponding author
} 


\section{INTRODUCTION}

Launched last December 17, 2011, the first satellite of the Pleiades system allows very high resolution images acquisition. This system is made of two "small satellites" (mass of one ton) offering a spatial resolution at nadir of 0.7 meters and a field of view of 20 kilometers. The second satellite will be launched end of 2012.

The great agility of those two satellites enables a daily access all over the world, which is a critical need for defence and civil security applications, and a coverage capacity necessary for the cartographic applications at scales better than those accessible to SPOT satellites family. Moreover, Pleiades has very high stereoscopic acquisition capacity to meet the fine cartography needs, notably in urban regions, and to bring information complementary to aerial photography.

ORFEO, the Pleiades Accompaniment Program, was set up by CNES, the French Space Agency, to prepare, accompany and promote the use and the exploitation of the images acquired by this very high resolution optical sensor, especially in public sector. It was initiated in 2004 and will last until the end of the first year of the satellite life. The objectives of this program are 1) to assess the thematic capability of the Pleiades system to produce the various services required by end-users for distinct domains (defence, risks, cartography, hydrology, forestry, agriculture, ...) and 2) to develop efficient tools to facilitate image information extraction by end-users.

Pleiades imagery will be available at Astrium GEO-Information Services (exclusive provider) with specific conditions and prices for public service European users, through a "Public Service Delegation" giving access to $40 \%$ of Pleiades resources. It was therefore a key issue to prepare the institutional community to this new data source. This paper presents the ORFEO program achievements (thematic and methodology) and its application during the first year of life of Pleiades-1A (April 2012 - June 2013).

\section{ORFEO ACOMPANIMENT PROGRAM: THE THEMATIC PART}

The Thematic part of the ORFEO accompaniment program covers a large range of applications, and aims at specifying and validating products and services required by users. An in-depth work of user needs assessments in eight domains (sea and coastline, risks and humanitarian aid, cartography and urban planning, geophysical hazards, hydrology, forestry, agriculture and defence) has given rise to a large number of feasibility studies from 2006 to 2011. Since 2006, more than 40 studies have been led by scientists and thematic experts from French and Belgium institutions, in close link with public end-users such as Ministry of Internal Affairs, Ministry of Ecology, French national cartographic institute, etc. Such studies, generally based on student internships, have been performed with imagery support provided by CNES both in optical domain (WorldView-2, QuickBird, Ikonos, GeoEye-1, Kompsat, Formosat, aerial images) and radar domain (TerraSAR-X, COSMO-SkyMed, aerial images).

Pleiades-1A is in orbit since December 2011. As soon as March 2012 , the ORFEO program entered in its final year with "users thematic commissioning" activities. This year is a direct followup of ORFEO program objectives and philosophy, aiming at supporting and encouraging institutional use of Pleiades, performing research, $\mathrm{R} \& \mathrm{D}$ and demonstration projects required by institutional actors. Free open-source image handling and processing tools set up in the ORFEO methodological part are provided, if needed, for easier access to data.

Such activities are performed in complementarity and in synergy with Astrium GEO-Information Services marketing activities, aiming at developing Pleiades market among commercial users and at setting up certified and qualified commercial services.

During the Users Thematic Commissioning phase, the most promising studies since 2006 are being assessed with Pleiades imagery, in the eight domains of interest. Several key issues such as response to crisis, urban planning, human pressure on coastlines, watershed cartography, forest management are thoroughly studied.

In addition, a number of technical key assets of Pleiades system are validated by users, such as covering a whole administrative region in a single pass (one orbit), creating a mosaic of 100x100 $\mathrm{km}^{2}$ with certified geometry and radiometry, acquiring multistereo data (tri or more) to extract altitude information not only on terrain, but also on buildings. Around 400-500 Pleiades images are specifically devoted to this thematic commissioning year, on about 50 sites around the world. Of course, geographic sites with major disasters or specific events not predictable will be covered so that Risks and Humanitarian activities can be performed during this period.

A specific seminar will be held in October 2013 to present the results of this large panel of public sector driven studies. Main French ministries (Ecology, Internal Affairs, Agriculture and Forestry...) and European bodies such as GMES project will be involved.

\section{ORFEO ACCOMPANIMENT PROGRAM: THE METHODOLOGICAL PART}

The Methodological Part of the ORFEO accompaniment program aims at preparing the use and exploitation of Pleiades sub-metric images. This preparation includes capitalising on image analysis $\mathrm{R} \backslash \& \mathrm{D}$ results and know-how, and assisting the work of the thematic group and more widely of the future users by providing them with algorithms, methods and easily available tools to visualise and process the images for their needs. To achieve this, CNES decided in 2005 to develop and maintain, in the frame of the ORFEO accompaniment program, the Orfeo ToolBox (OTB), an open-source remote sensing image processing library.

\subsection{The Orfeo ToolBox in a nutshell}

The Orfeo ToolBox (CNES, www.orfeo-toolbox.org, Inglada et al., 2009, Christophe et al., 2009)) is written in C++ on top of ITK (Insights Toolkit, www.itk.org), a medical image processing library, and interfaces seamlessly with other opensource image processing software such as GDAL (GeoData Abstraction Layer, www.gdal.org ) or OSSIM (Awesome Image Processing, www.ossim.org) . Orfeo ToolBox is released under the CeCILL Open source license (equivalent to GPL) and is available on multiple platforms (Windows, Linux and Mac OS $\mathrm{X})$. OTB comes with a modular architecture and natural 
scalability to images size and number of bands of most algorithms, thanks to native parallel and on the flow processing. The most straightforward way of using the Orfeo ToolBox is to write $\mathrm{C}++$ processing chain on top of it, while being guided by the extensive developer-oriented documentation OTB Soft Guide (0TB development team, 2011a). However, there are other lesser known means to use it, dedicated to nondevelopers.

The first one is to use the OTB Applications framework. It is a set of applications plugins that can be accessed through command-line, standalone QT graphical user interface, higherlevel coding languages such as Python for instance, and plugins for the QGIS software (Quantum GIS, www.qgis.org). This framework can be easily extended in two ways : first, one can very easily write new application plugins and access them through all the mentioned means, and second, one can easily use the application plugin interface to integrate all the available plugins into his own software environment.

The second and most end-user oriented mean to access OTB functionalities is to use Monteverdi, an integrated software for everyday life image manipulation and analysis task, which gives access to some of the most popular functionalities in OTB. Originally intended as a support for remote sensing training course and capacity building, Monteverdi has gained a lot of interest from the end-users community as a complete FOSS tool. Figures 1 and 2 show an example of processing module available in Monteverdi. Both the applications plugins and Monteverdi are thoroughly documented (OTB development team, 2011b).

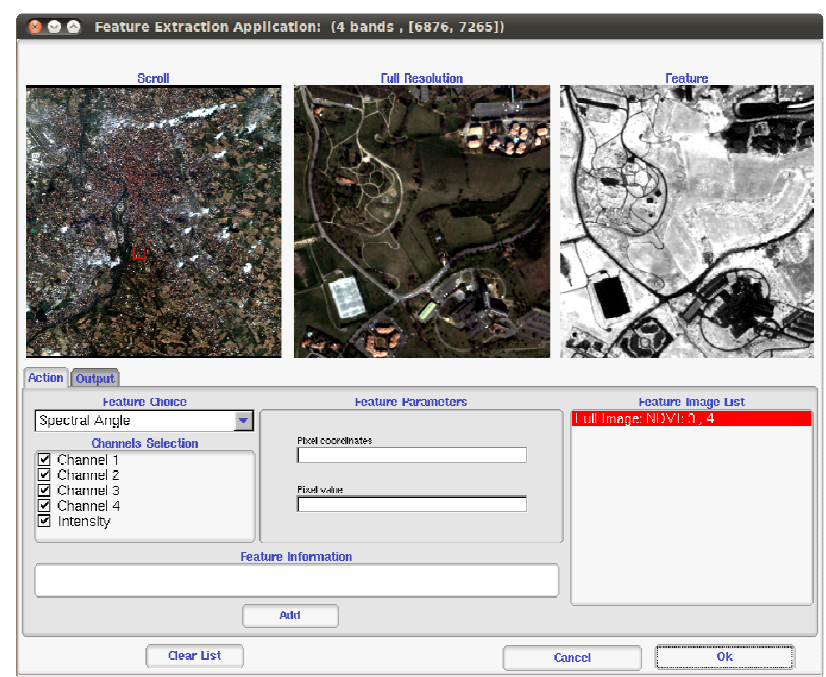

Figure 1. Monteverdi features extraction module

\subsection{What can be done with Orfeo ToolBox ?}

Being a rich and modular algorithms library, it is difficult to make a complete list of available functionalities. This section will present the most popular and useful. OTB can do all the basic image manipulation tasks: read, write, convert, rescale, resample, and extracts parts of remote sensing data. It can also perform basic pre-processing tasks like ortho-rectification, radiometric calibration or pan-sharpening. But the richness of Orfeo ToolBox lies in image processing: common processing tasks like thresholding, band-algebra, or Fourier and wavelets transforms, features extraction and segmentation, vectorization, classification and change detection, all including state-of-the-art algorithms.

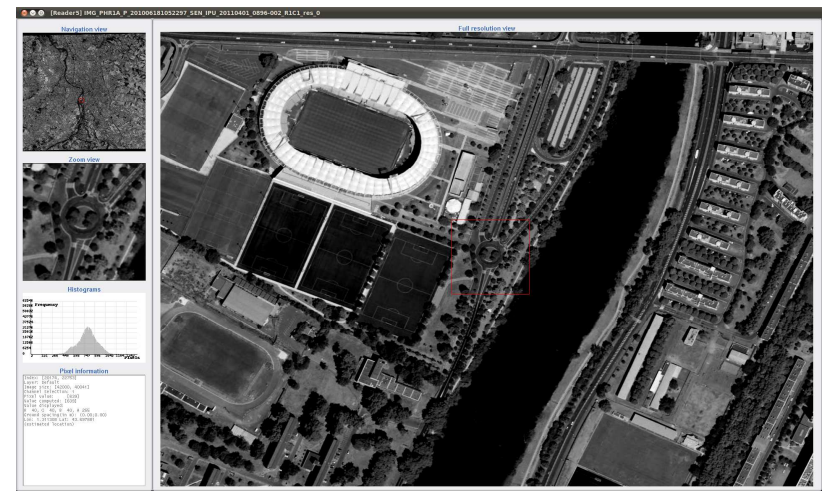

Figure 2. Monteverdi viewer on simulated Pleiades images

Being a rich and modular algorithms library, it is difficult to make a complete list of available functionalities. This section will present the most popular and useful. OTB can do all the basic image manipulation tasks: read, write, convert, rescale, resample, and extracts parts of remote sensing data Vldots It can also perform basic pre-processing tasks like ortho-rectification, radiometric calibration or pan-sharpening. But the richness of Orfeo ToolBox lies in image processing: common processing tasks like thresholding, band-algebra, or Fourier and wavelets transforms, features extraction and segmentation, vectorization, classification and change detection, all including state-of-the-art algorithms.

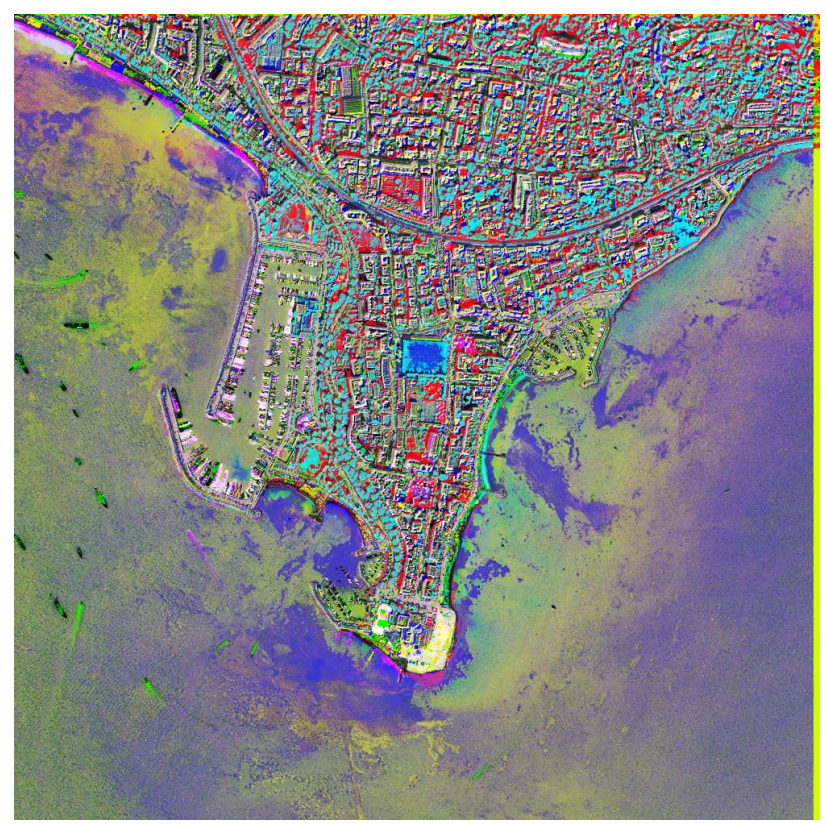

Figure 3. Example of Orfeo ToolBox algorithm results: MAD/MAF analysis (Nielsen et al., 2010) on a pair of 4 bands Worldview2 images of Cannes, France.

For example, Figure 3 shows the result of Multivariate Alteration Detection and Maximum Autocorrelation Factor change detection analysis (Nielsen et al., 2010) performed by OTB on a pair of 4 bands registered WorldView- 2 images, while Figure 4 shows the results of pan-sharpening and Line Segment Detection (von Gioi et al., 2010\} both performed by OTB on a Quickbird image. Advanced methodologies like 
Object Based Image Analysis or joint GIS-Image analysis are also available.

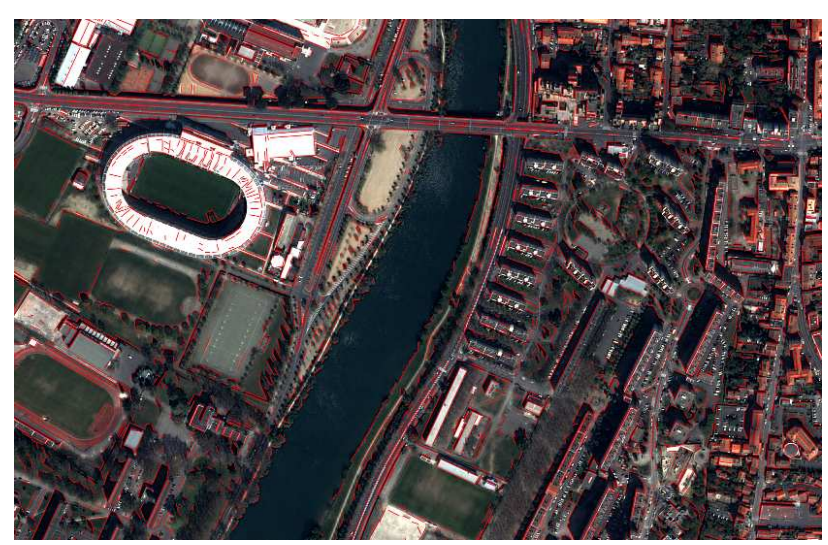

Figure 4. Example of Orfeo ToolBox algorithm results: Pansharpening and Line segment Detection on a Quickbird image of Toulouse, France.

\subsection{Support of Pleiades imagery}

Supporting the new Pleiades imagery in the Open source world was a great challenge for the OTB team, since the JPEG2000 format in which images are delivered is not yet commonplace, and since they are uncommonly huge: a standard product is 20 by 20 kilometers, sampled at 50 centimeters, with four spectral bands. To tackle this issue, CNES and the OTB team got involved in OpenJPEG (OpenJPEG, www.openjpeg.org ), one of the most advanced JPEG2000 Open source alternative. In cooperation with the OpenJPEG community, the software has been improved a lot and is now able to handle Pleiades imagery with reasonable performances. Additional contributions are to be made to OSSIM in order to share the support for Pleiades sensor modelling.

The result of all this work is that one can smoothly navigate in a Pleiades image through Monteverdi or the standalone OTB viewer, including access to the intermediate resolutions thanks to JPEG2000 features. The navigation experience on a decent computer will be rather nice, as shown in Figure 2. In addition to navigation, one can easily uncompressed parts or totality of a Pleiades image in reasonable time. Using Pleiades image as input to OTB or applications plugins processing chain, though on-the-flow decompression might become time-consuming for some algorithms, in which case prior decompression to disk is advised.

\section{CONCLUSION}

The actual capabilities and performances of the Pleiades system will be intensively tested during the thematic commissioning year. The very promising results already obtained in the calibration phase let think that images and system performances will be of excellent quality.

Meanwhile, three other key challenges have to be tackled by ORFEO team, both thematic and methodological. First, the large number of studies should demonstrate and concretely assess the benefit of sub-metric optical data for a large range of public sector users. Second, the Orfeo ToolBox Open source library, OTB applications and Monteverdi, should bring a real benefit to a large number of users (from $\mathrm{C}++$ developers to end- users), to use, manipulate and process these huge and incredibly rich images. Last, the ORFEO program should significantly and concretely demonstrate that Pleiades imagery is of great technical benefit for both public and commercial sectors. The final objective to reach is to show that such imagery can be efficiently integrated into operational processes, in order that decision makers include this new type of data into their usual tools.

\section{REFERENCES}

Christophe, E. and Inglada, J., 2009: Open source remote sensing: Increasing the usability of cutting-edge algorithms, IEEE Geoscience and Remote Sensing Newsletter

Inglada, J. and Christophe, E., 2009 : The Orfeo Toolbox remote sensing image processing software, Geoscience and Remote Sensing Symposium (IGARSS), 2009 IEEE International, , Vol 4, pp IV-733

Nielsen, A.A. and Hecheltjen, A. and Thonfeld, F. and Canty, M.J., 2010: Automatic change detection in RapidEye data using the combined MAD and kernel MAF methods, Geoscience and Remote Sensing Symposium (IGARSS), 2010 IEEE International, pp 3078-3081

OTB Development Team, 2011a: The ORFEO Tool Box Software Guide.

http://www.orfeo-toolbox.org/otb/documentation.html

OTB Development Team, 2011b: The Orfeo ToolBox Cookbook, a guide for non-developers

http://www.orfeo-toolbox.org/otb/documentation.html

von Gioi, R.G. and Jakubowicz, J. and Morel, J.M. and Randall, G., 2010: Lsd: A fast line segment detector with a false detection control, Pattern Analysis and Machine Intelligence, IEEE Transactions, 32(4), pp 722-732 